\author{
Arkadiusz GRUCELSKI ${ }^{1}$ \\ Jacek POZORSKI ${ }^{2}$
}

\title{
MODELOWANIE Z WYKORZYSTANIEM METODY SIATKOWEJ BOLTZMANNA TERMOMECHANIKI PRZEPLYWU WRAZ Z REAKCJAMI CHEMICZNYMI
}

\begin{abstract}
Szczegółowy opis oraz analiza termomechaniki w przepływie przez ośrodek porowaty wraz z następującym uwolnieniem składników chemicznych z ziaren ciała stałego ośrodka (reprezentujących biomasę, węgiel) zostaną zaprezentowane wraz z pierwszymi wynikami symulacji przy wykorzystaniu uproszczonego modelu odgazowania. Po wykonaniu podstawowych testów dla przepływu płynu oraz transportu ciepła, dodatkowe funkcje rozkładu zostały zaimplementowane w celu modelowania ewolucji emisji oraz transportu składników chemicznych. Koncentracja składników chemicznych (jako wynik symulacji) wyznaczona jako wynik prostych reakcji wykazuje dobrą zgodność z innymi metodami numerycznymi. Modelowanie procesu pirolizy wykonane zostało z wykorzystaniem referencyjnego odgazowania węgla dało pierwsze jakościowe wyniki, przy pewnym zauważalnym wzroście kosztów obliczeniowych. Dla wyższej dokładności oraz zmniejszenia złożoności obliczeniowej planujemy wykorzystanie uproszczonego opisu kinetyki chemicznej dla zjawiska odgazowania stałych cząstek paliwa (ciało stałe geometrii). W artykule wyjaśniono przepływ płynu z przejmowaniem ciepła przez reaktywne nośniki granulowane na poziomie reprezentatywnego elementu o objętości (REV), w tym także oddziaływania mechaniczne ziaren stałych spowodowane ich rozszerzalność cieplną.
\end{abstract}

Słowa kluczowe: LBM, termomechanika przepływu, modelowanie odgazowania, reprezentatywny element objętości

\section{Wprowadzenie}

Ze względu na trendy w energetyce widoczne od kilku lat pojawia się potrzeba wspierania projektów związanych z dostępnymi oraz bogatymi złożami paliw kopalnych, jak również dotyczących budowania biogazowni oraz optymalizacji działania istniejących instalacji wykorzystujących proces odgazowania.

\footnotetext{
${ }^{1}$ Autor do korenspondencji: Arkadiusz Grucelski Instytut Maszyn Przepływowych PAN, e-mail: agrucelski@imp.gda.pl

${ }^{2}$ Jacek Pozorski, Instytut Maszyn Przepływowych PAN, e-mail: jp@imp.gda.pl
} 
Należy nadmienić, iż nie sposób by było wykonywać obliczenia numeryczne szczegółowych zjawisk chemicznych (rozpad molekuł węgla) w jak najogólniejszym sensie (dla każdego rodzaju węgla oraz biomasy). $\mathrm{Z}$ tego powodu wykorzystywane są metody i schematy numeryczne takie jak narzędzia współczesnej mechaniki płynów bądź modele uproszczonej chemii dla której ziarna biomasy oraz węgla zostają podzielone na grupy (tzw. grupy funkcyjne) z których każda odpowiada za emisję odpowiedniego produktu gazowego pirolizy oraz każda dodaje pewien przyczynek do emisji składników smolistych (opis poniżej). Model odgazowania został zaimplementowany z powodzeniem przy wykorzystaniu metody siatkowej Boltzmanna (LBM); rozwijanej od kilku lat metody z powodzeniem wykorzystanej do opisu zjawisk cieplnych i przepływowych $[2,4,8]$ w przypadku ewolucji składników chemicznych, dodatkowa funkcja dystrybucji została dodana odpowiednio dla każdego składnika chemii oraz odpowiadającego mu członu źródłowego. Wyniki jakościowe uzyskane przy wykorzystaniu powyższych modeli oraz metody LB stanowią bezpośrednie poparcie tezy, iż LBM można z sukcesem wykorzystać przy modelowaniu przepływu masy, transportu ciepła oraz ewolucji składników chemicznych procesu odgazowania (biomasy oraz węgla, przy dodatkowej implementacji prostego modelu oddziaływania ciało stałe - ciało stałe co jest $\mathrm{z}$ powodzeniem modelowane przy wykorzystaniu LBM [5]. Modelowane zjawiska (na CPU) transportu ciepła oraz masy wraz $\mathrm{z}$ procesami odgazowania wykonywane są $\mathrm{w}$ ośrodku granularnym o losowym ułożeniu ziaren. Ze względu na charakter procesu, symulacja wykonywana jest na elemencie REV objętości w 2D oraz 3D. Na koniec rozdziału obok dyskusji pojawi się uzasadnienie dalszych prac, które są konieczne ze względu na znaczny koszt prowadzenia modelowania na opisanym poziomie.

Koksowanie jest powszechnie stosowanym procesem technologicznym stosowanym w celu uzyskania czystszego chemicznie węgla (koksu), benzenu oraz innych składników gazowych powszechnie znanych jako gaz koksowniczy oraz części smoliste. $Z$ punktu widzenia termomechaniki płynów, koksowanie zachodzi w złożu granularnym (zasyp ziaren węgla), które wskutek ogrzewania ulegają przekształceniu do jednolitego złoża porowatego. W trakcie trwania procesu koksowania skomplikowane zjawiska zachodzą na poziomie pojedynczego ziarna (pora); w obrębie tej geometrii w skład wchodzą przepływ płynu przez ośrodek, przewodzenie ciepła, uwalnianie związków chemicznych oraz plastyczne deformacje złoża stałego oraz inne.

\subsection{Zarys metody}

W prezentowanej pracy użyta została metoda siatkowa Boltzmanna (Lattice Boltzmann Method, LBM), w nomenklaturze której gęstość oraz prędkość przepływu są rozwiązywane poprzez ewolucję gęstości funkcji dystrybucji [7], ewolucja pola temperatury jest liczona z wykorzystaniem dystrybucję gęstości 
energii wewnętrznej (Internal Energy Density Distribution Function IEDDF $[2,9]$, natomiast ewolucja składników chemicznych jest modelowana przez wykorzystanie oddzielnej funkcji dystrybucji (innej dla każdego składnika chemii) [1]; forma wszystkich równań w LBM dla wspomnianych modeli jest identyczna. Wyczerpujący opis LBM dla przepływu płynu można znaleźć w podanych cytowaniach oraz $\mathrm{w}$ referencjach, natomiast $\mathrm{w}$ tej pracy tylko ogólne równania dla LBM zostaną przedstawione bez prezentacji szczegółów. Pewnym innowacyjnym aspektem pracy są funkcje równowagi dla ewolucji chemii, które dla D3Q15, w tej pracy zostały podane po raz pierwszy (według najlepszej wiedzy autorów).

Równania metody siatkowej Boltzmanna w postaci dyskretnej dla czasu oraz położenia (na siatce regularnej) oraz przestrzeni prędkości (na dyskretnych kierunkach zależnych od modelu dyskretyzacji $\mathbf{e}_{i}$ ) opisują ewolucję zadanego fizycznego pola przy wykorzystaniu funkcji dystrybucji ( $f$ dla składników chemicznych opisanych przez $\phi_{i, k}$ ). W naszym przypadku (symulacja procesu odgazowania) modelowany jest przepływ płynu, transport ciepła oraz ewolucja składników chemicznych:

$$
f_{i}\left(\mathbf{x}+\mathbf{e}_{i}, t+\delta t\right)-f_{i}(\mathbf{x}, t)=-\tau_{\nu}^{-1}\left(f_{i}(\mathbf{x}, t)-f_{i}^{e q}(\mathbf{x}, t)\right)+Q_{k},
$$

gdzie $f_{i}^{e q}$ reprezentuje stan równowagi funkcji dystrybucji odpowiedniego pola uśrednionego na siatce $(\mathrm{x}, \mathrm{t})$; człon równowagi posiada następującą postać:

$$
f_{i}^{e q}=\alpha \Omega_{i}\left(A_{i}+B_{i} \mathbf{e}_{i} \cdot \mathbf{u}+C_{i}\left(\mathbf{e}_{i} \cdot \mathbf{u}\right)^{2}-D_{i}(\mathbf{u})^{2}\right),
$$

gdzie $\mathbf{u}$ to lokalna prędkość płynu natomiast współczynniki $A_{i}$ do $D_{i}$ zależą tylko od schematu dyskretyzacji (D2Q9, D3Q15, itp.). Kompletny opis dla wszystkich równań (wraz z tablicami współczynników dla równania 2 dla przepływu płynu oraz transportu ciepła) w 2D oraz 3D można odnaleźć w [2, 7] z kompletnymi referencjami. Warto zwrócić jeszcze uwagę, iż równanie 2 wykazuje taką samą postać wielomianu w przypadku każdej funkcji rozkładu jednakże dla gęstości, energii wewnętrznej oraz składników chemicznych współczynniki $A, B, C, D$ zależą bądź nie, od kierunku $i$ (por. [5,8]), natomiast równanie ewolucji posiada zawsze analogiczną postać do równania 1 , natomiast człon $Q_{k}$ odpowiada członom źródłowym (dodany w celu uwzględnienia emisji składników chemicznych). W przypadku transportu masy, strumień wyrzucanych gazów (strumień masy na powierzchni przeszkody, dla IEDDF) jest opisany przez $Q_{k}=\Omega_{i} Y_{i, k}(\mathbf{x}, t) \rho_{k} \delta t$. W przypadku transportu ciepła człon źródłowy rozdziela się na człon na powierzchni powodujący zmniejszanie temperatury oraz człon źródłowy mający wpływ na IEDDF w objętości gazu. Równanie (1) zawiera parametr nazywany czasem relaksacji, który posiada znaczenie fizyczne 
w wykorzystywanej metodzie; dla przykładu, termiczny czas relaksacji dla fazy $m$ posiada następującą postać $[3,5,7]$ :

$$
\tau_{i}=0.5+\frac{3}{2} \frac{\lambda_{m}}{\rho_{m} C_{p m} \delta t}
$$

gdzie $\mathrm{m} \in\{s, f\}$ (w zależności od fazy) oraz $\delta t=1, C_{p m}$ jest to pojemność cieplna fazy $m, \lambda_{m}$ jest przepuszczalnością cieplną.

Uśrednione wartości pól makroskopowych w każdym węźle (temperatura, gęstość, naprężenia na powierzchni ziarna, koncentracja składników chemicznych, itp.) są uzyskiwane poprzez całkowanie funkcji rozkładu (po dyskretnych kierunkach przestrzeni prędkości siatkowej, $\mathbf{e}_{i}$ ). Ewolucja składników chemicznych $\mathrm{w}$ przypadku uwolnionych gazów jest modelowana $\mathrm{z}$ wykorzystaniem LBM przy pomocy dodatkowej funkcji dystrybucji dla każdego rozpatrywanego składnika chemicznego $k$. W przypadku modelowanego zjawiska, wysokie różnice koncentracji składników można zaobserwować; początkowa koncentracja danego składnika (w płynie) jest założona jako zerowa. Ze względu na zaobserwowane niestabilności, wykorzystany został schemat zaproponowany przez Di Rienzo i in. [1]. Zmodyfikowana postać funkcji równowagi dla schematu D2Q9 w LBM została zaprezentowana w postaci następującej:

$$
\begin{aligned}
& \phi_{0, k}^{e q}=\frac{\rho Y_{k}}{9}(9-5 \psi), \\
& \phi_{i=1, . ., 4 ; k}^{e q}=\frac{\rho Y_{k}}{9}\left(\psi+3 \mathbf{e}_{i} \cdot \mathbf{u}\right), \\
& \phi_{i=5, . ., 9 ; k}^{e q}=\frac{\rho Y_{k}}{36}\left(\psi+3 \mathbf{e}_{i} \cdot \mathbf{u}\right)
\end{aligned}
$$

modyfikacja dla D3Q15 została wykonana przez autorów:

$$
\begin{aligned}
& \phi_{0, k}^{e q}=\frac{\rho Y_{k}}{9}(9-7 \psi), \\
& \phi_{i=1, . ., 6 ; k}^{e q}=\frac{\rho Y_{k}}{9}\left(\psi+3 \mathbf{e}_{i} \cdot \mathbf{u}\right), \\
& \phi_{i=7, . ., 15 ; k}^{e q}=\frac{\rho Y_{k}}{72}\left(\psi+3 \mathbf{e}_{i} \cdot \mathbf{u}\right)
\end{aligned}
$$


gdzie $\phi_{i, k}^{\text {eq }}$ jest funkcją dystrybucji odpowiadającą elementowi $k$, w kierunku $i$, $\psi=\rho^{*} / \rho$ odpowiada stosunkowi minimalnej gęstości w całym obszarze do gęstości w danym punkcie.

Di Rienzo i in. [1] także wprowadzili zależność na czas relaksacji $\tau_{k} \sim\left(D_{k} / \psi\right)$, (dla porównania $\tau_{\nu} \sim \nu$ natomiast $\tau_{\theta} \sim \alpha$ ) gdzie $D_{k}$ jest współczynnikiem dyfuzji składnika $k$. Ze względu na występowanie zakrzywionego interfejsu na granicy faz płyn-ciało stałe w rozpatrywanej geometrii, schemat brzegowy wyższego rzędu został wykorzystany w rozpatrywanym modelu. Wyczerpujący opis schematu numerycznego z pewnymi obliczeniami dla testowych przypadków został zaprezentowany w [ag]; schemat brzegowy (dla brzegów zakrzywionych) został także rozwinięty dla IEDDF [4]. Dla obu funkcji dystrybucji gęstości oraz energii wewnętrznej na wlocie, nieznane wartości funkcji rozkładu rozwiązywane są z wykorzystaniem warunku Gradda [2]; natomiast na napływie, nierównowagowe rozwiązanie funkcji dystrybucji zostało przyjęte dla ekstrapolowanych wartości pól uśrednionych (gęstości oraz temperatury),

\section{Model chemii}

Podstawowy model odgazowania użyty w pracy został opisany przez Solomona $\mathrm{i}$ in. [6]. W swojej pracy autor wykorzystuje podejście grup funkcyjnych; w związku z tym model ziarna węgla został podzielony na grupy, z których każda odpowiada za emisję danego składnika gazowego oraz części smolistych. Tabela 1 przedstawia zbiór grup wraz z współczynnikami użytymi w równaniach szybkości przemiany odpowiedniego składnika. Równania są podane w formie $k_{k}=k_{k, 0} \exp \left(-\left(E_{k} / R\right) / T\right)$, gdzie $E_{k}$ to stała aktywacji. Pełny zbiór grup oraz produktów jest w podany w [6]. Ilość wytworzonych w czasie $\delta t$ gazów (z danej grupy funkcyjnej $k$ ) opisana jest następującym równaniem (jednorodnie rozłożonych na powierzchni),

$$
\delta W_{k}(\text { gaz })=k_{k} Y_{k}(\text { wegiel }) M_{k} \delta t
$$

natomiast ilość wytworzonych składników smolistych opisana jest równaniem wynikającym z sumowania po wszystkich grupach funkcyjnych ilości smoły wytworzonej w każdej z nich:

$$
\delta W_{k}(\operatorname{tar})=\sum_{k}\left(d n_{k} / d t\right) Y_{k} M_{\mathrm{tar}} \delta t
$$

gdzie wielkość $Y_{k}$ określa udział danej grupy (mającej udział w tworzeniu części smolistych) w określonym ziarnie węgla, natomiast $d n_{k} / d t$ jest ściśle powiązane z procesami transportu wewnątrz ziarna węgla. 
Tabela 1. Grupy funkcyjne oraz produkty gazowe wraz z równaniem szybkości przemiany

Table 1. Functional groups and gas products with the reaction rate equation

\begin{tabular}{l|c|c} 
grypa funkcyjna & gaz & równanie szybkości \\
\hline \multirow{3}{*}{ karboksylowa } & $\mathrm{CO}_{2}$ & $k_{1}=0.81 \cdot 10^{13} \exp (-22500 / T)$ \\
& $\mathrm{CO}_{2}$ & $k_{2}=0.65 \cdot 10^{17} \exp (-33850 / T)$ \\
& $\mathrm{CO}_{2}$ & $k_{3}=0.11 \cdot 10^{16} \exp (-38315 / T)$ \\
\hline \multirow{2}{*}{ hydroksylowa } & $\mathrm{H}_{2} \mathrm{O}$ & $k_{4}=0.22 \cdot 10^{19} \exp (-30000 / T)$ \\
& $\mathrm{H}_{2} \mathrm{O}$ & $k_{5}=0.17 \cdot 10^{14} \exp (-32700 / T)$ \\
\hline \multirow{3}{*}{ eterowa } & $\mathrm{CO}$ & $k_{6}=0.14 \cdot 10^{19} \exp (-40000 / T)$ \\
& $\mathrm{CO}$ & $k_{7}=0.15 \cdot 10^{16} \exp (-40500 / T)$ \\
& $\mathrm{CO}$ & $k_{8}=0.20 \cdot 10^{14} \exp (-45500 / T)$ \\
\hline & $\mathrm{HCN}$ & $k_{8}=0.17 \cdot 10^{14} \exp (-30000 / T)$ \\
& $\mathrm{HCN}$ & $k_{9}=0.69 \cdot 10^{13} \exp (-42500 / T)$ \\
& $\mathrm{NH}_{3}$ & $k_{10}=0.12 \cdot 10^{13} \exp (-27300 / T)$ \\
\hline \multirow{3}{*}{ metylowa } & $\mathrm{CH}_{4}$ & $k_{11}=0.84 \cdot 10^{15} \exp (-30000 / T)$ \\
& $\mathrm{CH}_{4}$ & $k_{12}=0.75 \cdot 10^{14} \exp (-30000 / T)$ \\
& $\mathrm{CH}_{4}$ & $k_{13}=0.34 \cdot 10^{12} \exp (-40500 / T)$ \\
\hline & $\mathrm{tar}$ & $k_{T}=0.86 \cdot 10^{15} \exp (-27700 / T)$
\end{tabular}

Tabela 2. Współczynniki podstawowych produktów gazowych rozerwania molekuł smoły

Table 2. Coefficients of basic gas products from tar molecules breakage

\begin{tabular}{|l|l|l|l|}
\hline Skł & $v_{j}$ & Skł & $v_{j}$ \\
\hline $\mathrm{CO}$ & $0.78 \cdot 0.72222$ & $\mathrm{CO}$ & $0.78 \cdot 0.14222$ \\
\hline $\mathrm{H}_{2}$ & $0.78 \cdot 0.02222$ & $\mathrm{H}_{2}$ & $0.78 \cdot 0.11334$ \\
\hline $\mathrm{tar}$ & -1.0 & $\mathrm{tar}$ & 0.22 \\
\hline
\end{tabular}

Ilość moli każdej grupy w ciele stałym okreslona jest na podstawie zależności wegiel) $\rho_{k} / M_{k}$ gdzie $\rho_{k}, M_{k}$ to gęstość i masa molowa danego składnika gazowego natomiast $\mathrm{V}$ objetość zajmowana przez ciało. Szczegóły dotyczące modelu pirolizy można odnaleźć w [6]. Poza zjawiskami odbywającymi się wewnątrz ziarna węgla (gdzie procesy chemii opisane są powyżej) w opisywanym modelu uwzględnione są jeszcze reakcje rozpadu części smolistych. Dodatkowe reakcje (reakcje homogeniczne) dotyczą rozpadu molekuł smoły na gazy podstawowe (w tym opracowaniu ${ }^{\cdots} \mathrm{H}_{2}, \mathrm{CH}_{4}$ ) które zachodzą zgodnie z następującą zależnością [9]:

$$
\begin{array}{r}
C O \mathrm{CO}(g)+\nu_{\mathrm{CO}_{2}} \mathrm{CO}_{2}(g)+\nu_{\mathrm{CH}_{4}} \mathrm{CH}_{4}(g)+ \\
\nu_{\mathrm{H}_{2}} \mathrm{H}_{2}(g)+\nu_{\mathrm{tar}_{\mathrm{i}}} \operatorname{tar}_{\mathrm{i}} d t
\end{array}
$$

Wartości poszczególnych współczynników zostały podane w tabeli 2, natomiast szybkość reakcji wynosi:

$$
047 \cdot 10^{5} \exp (-11230 / T) Y_{T}
$$


gdzie $\mathrm{Y}_{\mathrm{T}}$ określa koncentrację smoły; jak podaje Wurzenberger około $22 \%$ smoły nie ulega przemianie i jest opisane jako tar .

\section{Wyniki}

Rysunek 1 przedstawia wyniki dwóch przypadków testowych opływu pojedynczej przeszkody. Lewy rysunek (kierunek przepływu jest od dołu do górnej części) pokazuje linie stałego ciśnienia dla kilku liczb Prandtla. Jakościowa zgodność z wynikami eksperymentalnymi jest łatwo zauważalna, dokładna analiza jest $w$ trakcie przygotowania [4]. Gradienty pola temperatury na powierzchni od strony wlotu (węzły przeszkody posiadają stałą temperaturę) są coraz większe wraz ze wzrostem liczby Prandtla. Prawa część Rys. 1 przedstawia powiększony element wokół cylindra, gdzie uwidoczniony jest proces tworzenia się wirów.

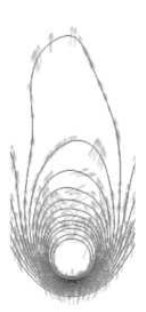

$\operatorname{Pr}=0.05$

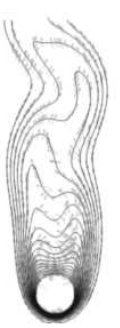

$\operatorname{Pr}=0.72$

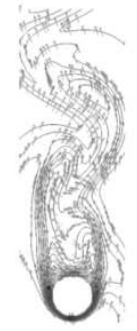

$\operatorname{Pr}=3.00$

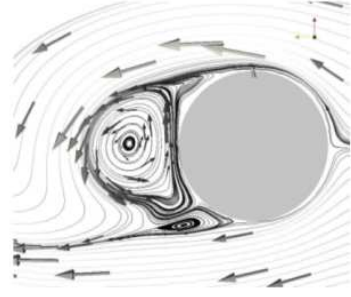

$\operatorname{Re}=500$

Rys. 1. Przypadki testowe symulacji LBM; po lewej: linie stałej temperatury dla kilku liczb Prandtla, po prawej: linie prądu wraz z wektorami prędkości podczas tworzenia wirów

Fig. 1. LBM benchmark results: the lines of constant tempearture for a few Prandtl numbers (left) and the current lines with velocity vector for a few Prandtl numbers during formation of vortices (right)

W przypadku modelowania procesu pirolizy model (Solomona i in. [6]) zaimplementowany $\mathrm{w}$ opisywanym narzędziu bazuje na pomyśle grup funkcyjnych dla łańcuchów węglowodorowych. Niestety, opisuje on ewolucję składników chemicznych przez rozwiązywanie równań Arrheniusa dla kolejnych składników chemicznych: dziewięć w przytaczanym modelu co (w nomenklaturze LBM) oznacza dziewięć dodatkowych funkcji dystrybucji, które (dla 3D) oznaczają znaczący wzrost czasu obliczeniowego. Rysunek 2 (po lewej) pokazuje wynik działania modelu odgazowania $\mathrm{w}$ pewnej chwili czasowej w prostym złożu granularnym (o wysokiej porowatości). Rysunek 2 (po prawej) pokazuje w jaki sposób szybkość odgazowania zależy od szybkości nagrzewania poprzez zauważalne przesunięcie wyników; wykres pokazuje uśrednione wyniki w zależności od składnika chemicznego (zielona linia, tutaj metan) wewnątrz objętości ziarna. 
Rysunek 3 przedstawia wyniki dla procesu odgazowania pojedynczego ziarna ogrzewanego strumieniem ciepłego płynu, wskutek rozpadu molekuł dochodzi do odgazowania; w modelowaniu zjawiska wykorzystano LBM w 3D przy wykorzystaniu równania 4 opracowanego na podstawie pracy Di Rienzo i in. [1]. Przedstawiony wynik obrazuje w funkcji czasu, zachowanie masy danego składnika chemicznego (opisanego w legendzie) uwalnianego $\mathrm{z}$ wnętrza ciała (w pierwszych chwilach czasowych, podano masę grupy funkcyjnej), podczas transportu w płynie oraz całkowitej masy przepływającą przez powierzchnię wylotu przy wykorzystaniu zależności (na strumień masy w punkcie) $m=\left.\int_{t} \sum_{i} \phi_{i, k} \mathbf{e}_{i}\right|_{y} d t$, gdzie sumowanie odbywa się tylko po składowej $y$ wektora prędkości siatkowej $\mathbf{e}_{i}$. Otrzymana masa danego składnika jest odniesiona do całkowitej masy ziarna ciała stałego. Rysunek 4 przedstawia wynik odgazowania $\mathrm{w} 3 \mathrm{D} \mathrm{w}$ przepływie przez prosty ośrodek porowaty wraz $\mathrm{z}$ koncentracją jednego składnika w płynie. Wynik osiągnięto na względnie rzadkiej siatce 50x50x50, co powoduje wahania całkowitej masy: wydaje się, że ilość w płynie jest mniejsza od tej jaka powinna być obserwowana (licząc masę odgazowanego składnika oraz efekt przemiany części smolistych); całkowita masa jaka opuszcza obszar obliczeniowy prezentuje już lepszą zgodność z założeniami. Praca nad pełnym i poprawnym opisem odgazowania dla modelowania 3D są jeszcze w trakcie rozwoju.
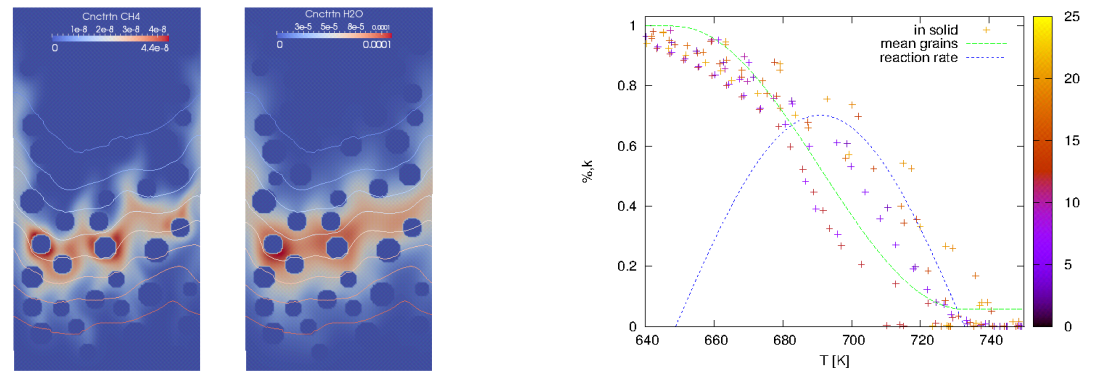

Rys. 2. Wyniki emisji gazów z wnętrza ziaren wskutek ogrzewania (po lewej) oraz stopień odgazowania w zależności od temperatury dla kilkunastu ziaren (po prawej)

Fig. 2. The results of the emission of gases from the interior of the grains as a result of heating (left) and the degree of degasification in dependence on a function of temperature for several grains (to the right)

\section{Podsumowanie}

Praca przedstawia zarys metody oraz pewne szczegóły implementacji narzędzie do modelowania zjawisk cieplno przepływowych wraz z zaimplementowaną chemią w złożu granularnym. Długofalowym celem jest stworzenie narzędzia wspomagającego modelowanie zjawisk odgazowania. W tym celu wykonane zostały obliczenia transportu ciepła oraz masy, natomiast ostatnio emisji składników (zgodnie z modelem odgazowania) w prostej geometrii. Obok wyników z przypad- 
ków testowych przedstawione zostały pierwsze (jakościowe) wyniki symulacji odgazowania zbioru ziaren w 3D. Otrzymany wynik pokazuje realne możliwości LBM w modelowaniu zjawisk zachodzących $w$ pewnej reprezentatywnej objętości zasypu (w tym przypadku) węgla. Kolejnym krokiem w osiągnięciu narzędzia zdolnego do modelowania połączonych zjawisk podczas odgazowania będzie przyspieszenie obliczeń w 3D (poprzez uproszczenie chemii oraz zmianę platformy do obliczeń z CPU na GPU) oraz uruchomienie modelu odkształceń plastycznych ziaren [5].

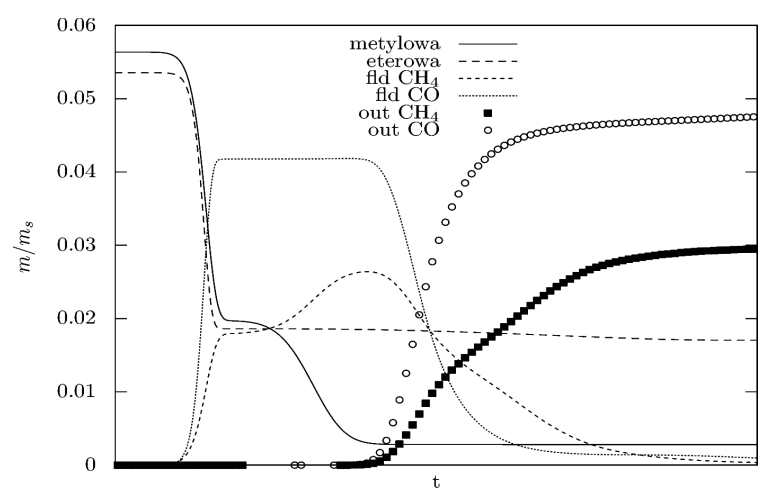

Rys. 3. Stosunek masy gazów produktów odgazowania stałej cząstki w 3D (fld - ilość gazów w płynie, out - ilość gazów która opuściła obszar obliczeniowy)

Fig. 3. Ratio of gas mass of products released in a result of degasification of the 3D solid grain (fld - the amount of gases in a fluid, out - the amount of gases left computational domain)

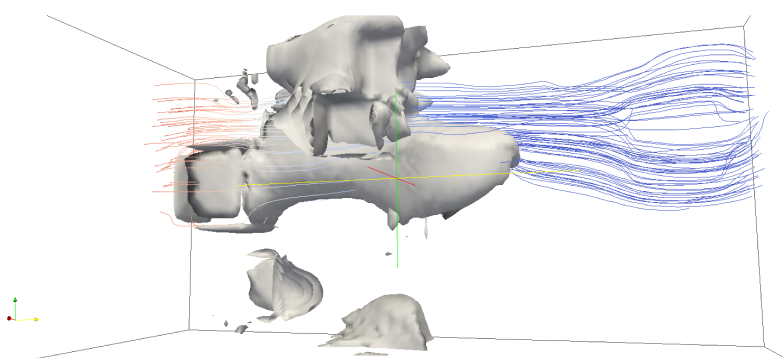

Rys. 4. Rysunek chwili czasowej symulacji 3D; powierzchnia określa koncentracje $\mathrm{H}_{2} \mathrm{O}$ uwo nionego z kilku ziaren, linie prądu kolorowane są zgodnie $\mathrm{z}$ temperaturą płynu

Fig. 4. Time stamp of 3D simulation, isosurface shows concentration of $\mathrm{H}_{2} \mathrm{O}$ released from a few grains, stream lines are coloured in accordance with temperature of the fluid

\section{Literatura}

[1] Di Rienzo A.F., Asinari P., Chiavazzo E., Prasianakis N.I., Mantzaras J.: Lattice Boltzmann model for reactive flow simulations, Eur. Phys. Lett., 98 (2012) pp. 34001 . 
[2] Grucelski A., Pozorski J.: Lattice Boltzmann simulations of flow past an obstacle and in simple porous media, Comp. Fluids, 71 (2013) 406-416.

[3] Grucelski A., Pozorski J.: Lattice Boltzmann simulation of fluid flow in porous media of temperature-affected geometry, J. Theor. Appl. Mech., 50 (2012) 193-214.

[4] Grucelski A., Pozorski J.: Lattice Boltzmann simulations of heat transfer in flow past a cylinder and in simple porous media, Int. J. Heat Mass Transfer, 2014, [in review].

[5] Han K., Feng Y.T., Owen D.R.J.: Numerical simulations of irregular particle transport in turbulent flows using coupled LBM-DEM, Comp. Modelling Eng. Sci. Vol. 18, 2007, pp. 87--100

[6] [6] Solomon P.R., Hamblen D.G., Carangelo R.M., Serio M.A., Deshpande G.V.: General model of coal devolatilization, Energy and Fuels, vol. 4, 1988, pp. 405-422

[7] Succi S.: The Lattice Boltzmann Method for Fluid Dynamics and Beyond, Clarendon Press, Oxford 2001

[8] Wang J., Wang M., Li Z.: A lattice Boltzmann algorithm for fluid-solid conjugate heat transfer, Int. J. Thermal Sci., vol. 46, 2007, pp. 228-234

[9] Wurzenberger J.C., Wallner S., Raupenstrauch H., Khinast J.G.: Thermal conversion of biomass: Comprehensive reactor and particle modeling, AIChE Journal, vol. 48, 2002, pp. 2398-2411

\section{LATTICE BOLTZMANN METHOD FOR THERMOMECHANICS OF FLUID FLOW WITH CHEMICAL REACTIONS}

\section{S u m m a r y}

A detailed description of thermomechanics of fluid flow through porous media with a release of chemical compounds from grains of solid fuel particles (biomass, coal, etc.) is presented together with first simulation results of a simplified model for degasification process. After the basic tests for fluid flow and heat transport, additional distribution functions are implemented to model the evolution of both emission and transport of chemical components. The concentration of chemical components (as a result of the simulation) is determined as a result of simple reactions shows good agreement with other numerical methods. A simulation of the pyrolysis process with the use of a simple reference model of coal degasification, gives first quantitative results along with a notable increase of computational cost. For higher accuracy and reduction of the computational complexity we plan to use a simplified description of the chemical kinetics of the phenomenon of degasification of solid fuel particles (solid geometry). In the article we account here for fluid flow with heat transfer through reactive granular media at the level of a representative element of volume (REV) including also mechanical interactions of solid grains due to their thermal expansion.

Keywords: LBM, thermomechanics, degasification modeling, representative element of volume

DOI: $10.7862 / \mathrm{rm} .2014 .39$

Otrzymano/received: 25.05 .2014

Zaakceptowano/accepted: 28.06.2014 